\title{
A Child with Bulky Kidneys and Renal Failure
}

\begin{abstract}
Acute lymphoblastic leukemia (ALL) is the most common malignancy in children. Acute renal failure is a well-recognized complication of ALL after initiation of chemotherapy. Renal failure as the primary manifestation of ALL with no evidence of tumor lysis is rare.
\end{abstract}

Keywords: Acute lymphoblastic leukemia, acute renal failure, lymphoblastic lymphoma, lymphoma

\section{Introduction}

Acute lymphoblastic leukemia (ALL) is the most frequent childhood malignancy. ${ }^{[1]}$ Leukemic infiltration of the kidneys is more common in the late stage of ALL and lymphoblastic lymphomas in all age groups and is reported to occur in $7 \%-42 \%$ of childhood leukemia cases. ${ }^{[2,3]}$ Acute renal failure has a variety of etiologies, but when associated with acute leukemia, it is typically due to therapy-related side effects, metabolic changes arising from chemotherapy, septicemias, nephrotoxic drugs, and leukemic infiltration of kidneys. ${ }^{[4]}$ Acute renal failure with hyperuricemia is a well-recognized complication of tumor lysis syndrome, and it occurs before or after the initiation of chemotherapy. ${ }^{[4]}$ However, initial presentation of acute leukemia as bilateral renal enlargement with renal failure with normal uric acid level is rather rare. ${ }^{[2,3]}$ Here, we report one such case.

\section{Case Report}

A 6-year-old boy presented to us with a history of fever for a month. Fever was high-grade intermittent not associated with rigors. Over next few days, he developed hurried breathing and was admitted to a local hospital and started on intravenous antibiotics for suspected pneumonia. Investigations showed hemoglobin of $6.8 \mathrm{~g} \%$, high white blood count (WBC) of 22,200 cells/cumm (neutrophils 38\%, lymphocytes $59 \%$, and eosinophils $3 \%$ ), and platelet count of 1.1 lakhs/cumm. His chest X-ray was normal. However, renal

This is an open access journal, and articles are distributed under the terms of the Creative Commons Attribution-Non Commercial-ShareAlike 4.0 License, which allows others to remix, tweak, and build upon the work non-commercially, as long as appropriate credit is given and the new creations are licensed under the identical terms.

For reprints contact: reprints@medknow.com functions were altered with serum creatinine of $2 \mathrm{mg} / \mathrm{dl}$, sodium of $132 \mathrm{mEq} / \mathrm{L}$, and serum potassium of $2.8 \mathrm{mEq} / \mathrm{L}$. The bone profile showed calcium of $7.6 \mathrm{mg} / \mathrm{dl}$ and alkaline phosphatase of 450 IU. Urine analysis showed $\mathrm{pH}$ of 7.5 with no evidence of urine infection. The blood and urine cultures were negative. Abdominal ultrasonogram revealed bulky kidneys with the right kidney of $9 \mathrm{~cm} \times 6 \mathrm{~cm}$ and left kidney of $10 \mathrm{~cm} \times 5 \mathrm{~cm}$. He was thought to have renal tubular acidosis with renal failure in view of compensated metabolic acidosis and started on sodium bicarbonate tablets, calcium, and Vitamin D supplements. However, the child continued to have low-grade fever with tachypnea for over 2 weeks and so was transferred to a tertiary care hospital. His initial investigations showed hemoglobin - $7.3 \mathrm{~g} \%$, WBC $-10,800$ cells/cumm (neutrophils - $44 \%$, lymphocytes - $54 \%$, and eosinophils - $2 \%$ ), serum creatinine - $1.6 \mathrm{mg} / \mathrm{dl}$, and erythrocyte sedimentation rate (ESR) - $130 \mathrm{~mm} / \mathrm{h}$, and peripheral smear was normal with no evidence of abnormal cells. Repeat ultrasound abdomen confirmed bilateral enlarged kidneys with coarse echotexture. Abdominal computed tomography scan confirmed the large-sized kidneys [Figure 1a]. His electrolytes, liver function test, calcium $(7.8 \mathrm{mg} / \mathrm{dl})$, phosphorous $(3.2 \mathrm{mg} / \mathrm{dl})$, lactate dehydrogenase $(256 \mathrm{U} / \mathrm{L})$, and uric acid $(1.2 \mathrm{mg} /$ dl) done were within normal range. The chest X-ray showed moderate left-sided pleural effusion [Figure 1b]. Arterial blood gas analysis showed $\mathrm{pH}-7.38, \mathrm{pCO}_{2}-26 \mathrm{mmHg}, \mathrm{pO}_{2}-54$ $\mathrm{mmHg}$, bicarbonate - $18.3 \mathrm{mEq} / \mathrm{L}$, and

How to cite this article: Shenoy $R$, Moideen $F$, Lashkari HP. A child with bulky kidneys and renal failure. Indian J Med Paediatr Oncol 2018;39:388-90.

\section{Ramnath Shenoy, Faheem Moideen, Harsha Prasada Lashkari}

Department of Pediatric Oncolgy and Paediatrics, KMC Hospital, Manipal University, Mangalore, Karnataka, India

Address for correspondence: Dr. Harsha Prasada Lashkari, KMC Hospital,

Manipal University, Mangalore - 575001 ,

Karnataka, India.

E-mail: harsha.pl@manipal.edu

Access this article online

Website: www.ijmpo.org

DOI: 10.4103/ijmpo.ijmpo_196_16 Quick Response Code:

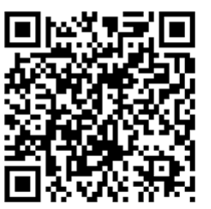




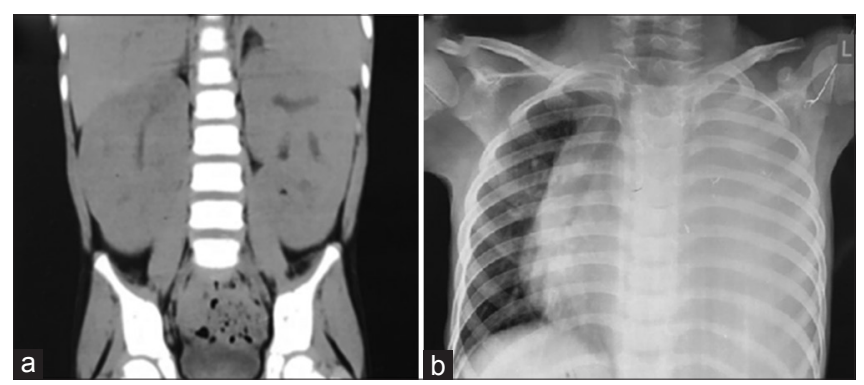

Figure 1: (a) Abdominal computed tomography images showing the bulky kidneys performed on admission to the tertiary hospital. (b) The chest X-ray showing left-sided pleural effusion

base excess - $6.8 \mathrm{mEq}$. The child was thought to have disseminated tuberculosis (TB) in view of persistent fever spike, cough, pleural effusion, high ESR, and hepatosplenomegaly and started on antitubercular treatment. Urine culture showed no growth. As the respiratory distress was increasing, video-assisted thoracoscopic surgery was done, and pleural fluid was sent for acid-fast bacilli and for GeneXpert TB test. Pleural fluid cytology showed plenty of lymphoblasts and GeneXpert test was negative for TB. Antitubercular treatment was stopped and was transferred to pediatric oncology department. The bone marrow aspiration done 8 days after starting treatment showed $12 \%$ of blasts. He was diagnosed with T-cell leukemia and started on chemotherapy under regimen C of UKALL 2003 protocol. His renal function normalized after chemotherapy was started and renal size became normal for the age by the end of induction. Day 29 of induction minimal residual disease was $<0.01 \%$. Currently, he is on the third maintenance cycle of ALL therapy and is doing well.

\section{Discussion}

Acute renal failure due to tumor lysis is a more common manifestation in ALL. ${ }^{[5-7]}$ It usually occurs by two mechanisms. The first one is uric acid nephropathy due to intratubular precipitation of uric acid causing mechanical obstruction, direct toxicity to epithelial and endothelial cells, and potentially activation of the innate immune system. ${ }^{[5-7]}$ The second one is hyperphosphatemia causing intrarenal calcium phosphate precipitation and direct tubular toxicity of phosphate. ${ }^{[8,9]}$ Standard prophylaxis of oral allopurinol to block uric acid formation or injection rasburicase (urate oxidase) coupled with intravenous hydration has dramatically reduced the incidence of uric acid nephropathy but not eliminated it. ${ }^{[10]}$

Leukemic infiltration of the kidneys is reported to occur in $7 \%-42 \%$ of childhood leukemia cases. It usually seen in the late stages of ALL in all age groups. ${ }^{[2,3]}$ In contrast, bilateral symmetrical renal enlargement at the time of diagnosis of ALL or lymphoblastic lymphoma is an infrequent finding, being present in $3 \%-5 \%$ of cases. ${ }^{[11]} \mathrm{A}$ potential mechanism for leukemic infiltration due to interaction of the chemokine receptor CXCR4, which is expressed on ALL cells, and its ligand stromal cell-derived factor-1 produced by stromal cells in bone marrow and extramedullary organs. Crazzolara et al..$^{[12]}$ reported that CXCR4 and its ligand play an important role in extramedullary invasion. ${ }^{[12]}$

There are different opinions about prognosis for children with leukemic renal involvement and resultant bulky kidneys. D'Angelo et al. ${ }^{[13]}$ assessed the prognostic value of bulky kidneys in children at time of diagnosis with ALL. They reported poorer event-free survival in a group with nephromegaly that was treated with nonintensive protocols than in a group without nephromegaly. In contrast to these findings, Neglia et al..$^{[14]}$ found that when kidney size was analyzed as a single variable and when it was considered after adjustment for the known prognostic factors of age, sex, and initial WBC count, enlarged kidney size at diagnosis of ALL in childhood was not associated with overall poorer survival.

\section{Conclusion}

As a conclusion, few cases of bilateral bulky kidneys in childhood acute leukemia were reported in literature. Renal involvement of acute leukemia or lymphoma should be considered in a child presenting with unexplained bilateral renal enlargement and fever with or without renal function abnormalities. Bone marrow examination should be included in the workup. With the availability of current evidence, we do not know the prognostic value of bulky kidneys in children with ALL.

\section{Financial support and sponsorship}

Nil.

\section{Conflicts of interest}

There are no conflicts of interest.

\section{References}

1. Belson M, Kingsley B, Holmes A. Risk factors for acute leukemia in children: A review. Environ Health Perspect 2007;115:138-45.

2. Ali SH, Yacoub FM, Al-Matar E. Acute lymphoblastic leukemia presenting as bilateral renal enlargement in a child. Med Princ Pract 2008;17:504-6.

3. Hann IM, Lees PD, Palmer MK, Gupta S, Morris-Jones PH. Renal size as a prognostic factor in childhood acute lymphoblastic leukemia. Cancer 1981;48:207-9.

4. Lommatzsch SE, Bellizzi AM, Cathro HP, Rosner MH. Acute renal failure caused by renal infiltration by hematolymphoid malignancy. Ann Diagn Pathol 2006;10:230-4.

5. Conger JD. Acute uric acid nephropathy. Med Clin North Am 1990;74:859-71.

6. Johnson RJ, Kivlighn SD, Kim YG, Suga S, Fogo AB. Reappraisal of the pathogenesis and consequences of hyperuricemia in hypertension, cardiovascular disease, and renal disease. Am J Kidney Dis 1999;33:225-34.

7. Jerome KR, Corey L. The danger within. N Engl J Med 2004;350:411-2. 
8. Boles JM, Dutel JL, Briere J, Mialon P, Robasckiewicz M, Garre $\mathrm{M}$, et al. Acute renal failure caused by extreme hyperphosphatemia after chemotherapy of an acute lymphoblastic leukemia. Cancer 1984;53:2425-9.

9. Zager RA. Hyperphosphatemia: A factor that provokes severe experimental acute renal failure. J Lab Clin Med 1982;100:230-9.

10. Cairo MS, Bishop M. Tumour lysis syndrome: New therapeutic strategies and classification. Br J Haematol 2004;127:3-11.

11. Mantan M, Singhal KK, Sethi GR. Acute lymphoblastic leukemia: An unusual cause of nephromegaly in infancy. Indian J Pediatr 2010;77:583.

12. Crazzolara R, Kreczy A, Mann G, Heitger A, Eibl G,
Fink FM, et al. High expression of the chemokine receptor CXCR4 predicts extramedullary organ infiltration in childhood acute lymphoblastic leukaemia. Br J Haematol 2001;115:545-53.

13. D'Angelo P, Mura R, Rizzari C, Conter V, Bellini F, Valsecchi MG, et al. Prognostic value of nephromegaly at diagnosis of childhood acute lymphoblastic leukemia. Acta Haematol 1995;94:84-9.

14. Neglia JP, Day DL, Swanson TV, Ramsay NK, Robison LL, Nesbit ME Jr., et al. Kidney size at diagnosis of childhood acute lymphocytic leukemia: Lack of prognostic significance for outcome. Am J Pediatr Hematol Oncol 1988;10:296-300. 